by the content of the first issue. Of fourteen articles, seven are concerned either wholly or partly with man but only four of these deal with problems relating to human evolution. Of the remaining seven, five papers deal with problems in primate genetics and taxonomy; one further paper discusses archaeological dating techniques and the last is a study of drift in primate groups which "might provide us with a tool" in the analysis of certain hominid groups.

The book review section certainly is not au courant. One wonders what the point can be of reviewing a book published six years ago (The Foundations of Genetics, by F. A. E. Crew, 1966). The remainder, published in 1970 , are merely 1.5 to 2 years old. The somewhat innovative "Book News" section, however, is useful. While none of the included books is particularly new, the device of presenting the table of contents is highly informative and lends objectivity to the inevitably subjective business of book reviews.

While a number of other regularly available periodicals publish this same range of material (and more recent book reviews) it must be pointed out that the quality of the articles in this first issue is high and they seem to be well researched and carefully presented. In addition, Chiarelli has assembled an editorial board which is impressive both in size and reputation.

Gail Kennedy

\section{Polymer Handbook}

Fibres, Films, Plastics and Rubbers: a Handbook of Common Polymers. Compiled by W. J. Roff and J. R. Scott. Pp. 688. (Butterworth: London, January 1972.) £15.

THE original version of the volume under review, entitled Fibres, Plastics and Rubbers, was compiled by W. J. Roff and published in 1956 . It received wide and well-merited acclaim as a unique work of reference on the properties of polymers then in common use. Since that time, published information on polymers has proliferated, many new types have become commercially available, and polymers in multifarious forms have penetrated almost every area of scientific and industrial activity. Consequently the need became increasingly apparent for a detailed revision and expansion of the earlier work, a rather daunting task which was undertaken by the two senior compilers with the assistance of staff of the Shirley Institute and of the Rubber and Plastics Research Association. The completed result of their collaboration has now appeared and in every way it can be regarded as a worthy successor to the original book.

All major classes of industrially useful synthetic and natural polymers are treated in the first forty-two sections, each dealing with a generic type and containing, in systematic order, detailed information on structure, chemical, general physical, thermal, mechanical and electrical properties; also given are brief notes on fabrication, serviceability, utilization and history. Separate discussion of individual properties and related topics occupies a further thirty-four sections, in most of which are given comparison tables listing polymers in order of magnitude of the respective property. The user can therefore rapidly scan the polymer-property matrix both horizontally and vertically. Sufficiently comprehensive lists of references are appended to each section, and indexes by author, trade-name and subject are provided.

The compilers have achieved a remarkable feat of compression, with a degree of attention to detail and manner of presentation that is nowadays rare. Accordingly, only relatively minor criticisms can be made. Perhaps the most serious of these is that the non-specialist reader is given insufficient warning of possibly large variations in polymer properties with temperature and timescale of measurement. Although such effects are discussed in general terms, almost all the numerical data are singlepoint values; the inclusion of some figures illustrating time- and temperature-dependence (for example, creep) for some of the more common plastics would have served to emphasize this characteristic feature of polymer behaviour. Neither melt flow properties nor crystalline morphology are discussed. Metric units are used throughout, but appropriate conversion factors are supplied together with a short note on SI units. $\quad$ P. F. ONYON

\section{Living Mechanisms}

Biomechanics: its Foundations and Objectives. Edited by Y. C. Fung, N. Perrone and $\mathrm{M}$. Anliker. Pp. xiii + 641. (Prentice-Hall: Englewood Cliffs, New Jersey, 1972.)

This book is the edited proceedings of a symposium of the same title held at the University of California in 1970. Biomechanics is presented as a subject of the moment, giving fresh impetus to biology and medicine as the old descriptive and phenomenological approach becomes exhausted. Two-thirds of the contributors are engineers from departments of engineering or bioengineering and only one is from an institute that incorporates biomechanics in its title.

The main theme of the contributions is the mechanical aspects of cardiovascular and pulmonary structures, although skin, tendon, bone and the mechanics of injury also receive considerable attention. The contents of Parts 2 to 3 are very welcome both for their comprehensive recent bibliography and a presentation of how engineers approach the properties of biological structures and materials. One might have wished for a stronger dialogue between the biologist and the engineer. The methods of approach, both experimental and mathematical must surely yield practical returns, although more authors seem to be treading a path from organism to model at present than vice versa. Few review texts exist in these selected fields and the work deserves a place as a sourcebook in every department that is concerned with relationships between structure and mechanical function of biological material. Those in surgery and orthopaedics who are contemplating collaboration with bioengineers will also be repaid by study of the book because it will help them to ask the right sort of question.

Biomechanics, a term which would have implied or at least embraced studies of the intact body in the nineteenth century, is used here to describe a mixture of bioengineering and what was termed biophysics fifteen years ago. Students of physical education and kinesiology who turn to this book hoping to find the long-awaited and advanced treatment of what they call biomechanics will be disappointed. Muscle (apart from myocardium) rates only six pages, without a bibliography, and the mechanical analysis of body movement likewise receives scant attention, apart from an excellent chapter on biomechanics and the amputee.

The foundations of the subject are not discussed and the contribution to Part 1 , which deals very readably with the objectives of the subject in physiology and surgery and rather obscurely with those in patient care and rehabilitation, surprisingly quotes only four publications before 1960. Physical scientists have contributed to physiology for a long time. It is more the appearance of the engineers as a professional group on the biological scene that is novel, rather than the approach. If muscle, for example, had received the review it deserves under the title of this book, it would have been more apparent that biomechanics developed in a century, not a decade.

D. W. Grieve 